\title{
"We're Going to Leave You for Last, Because of How You Are": Transgender Women's Experiences of Gender-Based Violence in Healthcare, Education, and Police Encounters in Latin America and the Caribbean
}

\author{
Michele Lanham, MPH, Kathleen Ridgeway, MSPH, ${ }^{1}$ Robyn Dayton, MPH, \\ Britany M. Castillo, Claire Brennan, MPH, Dirk A. Davis, MPH,, Dadrina Emmanuel, \\ Giuliana J. Morales, MPH, ${ }^{1}$ Clifford Cheririser, Brandy Rodriguez, Juana Cooke, MA, \\ Karin Santi, MA, and Emily Evens, MPH, $\mathrm{PhD}^{1}$
}

\begin{abstract}
Transgender (trans) women experience gender-based violence (GBV) throughout their lives, which impedes their access to services and contributes to poor health outcomes and quality of life. To inform policies and health programs, trans women worked with the United States Agency for International Development (USAID)- and President's Emergency Plan for AIDS Relief (PEPFAR)-supported LINKAGES project, the United Nations Development Programme, The University of the West Indies, and local organizations to document experiences of GBV and transphobia in healthcare, education, and police encounters. Trans women conducted 74 structured interviews with other trans women in El Salvador, Trinidad and Tobago, Barbados, and Haiti in 2016. We conducted qualitative applied thematic analysis to understand the nature and consequences of GBV and transphobia and descriptive quantitative analysis to identify the proportion who experienced GBV in each context. A high proportion experienced GBV in education (85.1\%), healthcare (82.9\%), from police (80.0\%), and other state institutions (66.1\%). Emotional abuse was the most common in all contexts and included gossiping, insults, and refusal to use their chosen name. Participants also experienced economic, physical, and sexual violence, and other human rights violations based on their gender identity and expression. At school, participants were physically threatened and assaulted, harassed in bathrooms, and denied education. In healthcare, participants were given lower priority and received substandard care. Healthcare workers and police blamed participants for their health and legal problems, and denied them services. From police, participants also experienced physical and sexual assault, theft, extortion for sex or money, and arbitrary arrest and detention. Participants had difficulty obtaining identification documents that matched their gender identity, sometimes being forced to alter their appearance or being denied an identification card. Service providers not only failed to meet the specific needs of trans women but also discriminated against them when they sought services, exacerbating their economic, health, and social vulnerability. Although international and regional resolutions call for the legal protection of transgender people, states do not meet these obligations. To respect, promote, and fulfill trans women's human rights, governments should enact
\end{abstract}

\footnotetext{
${ }^{1}$ FHI 360, Durham, North Carolina.

${ }^{2}$ ASPIDH Arcoíris, San Salvador, El Salvador.

${ }^{3}$ Community Education Empowerment \& Development, Bridgetown, Barbados.

${ }^{4}$ SEROvie, Petite Rivière de l'Artibonite, Haiti.

${ }^{5}$ Trinidad and Tobago Transgender Coalition, Port of Spain, Trinidad and Tobago.

${ }^{6} \mathrm{HIV}$, Health and Development, United Nations Development Programme, Panama City, Panama.
}

(C) Michele Lanham et al. 2019; Published by Mary Ann Liebert, Inc. This Open Access article is distributed under the terms of the Creative Commons Attribution Noncommercial License (http://creativecommons.org/licenses/by-nc/4.0/) which permits any noncommercial use, distribution, and reproduction in any medium, provided the original author(s) and the source are cited. 
and enforce antidiscrimination and gender-affirming laws and policies. Governments should also sensitize providers to deliver gender-affirming services.

Keywords: transgender, key populations, Latin America, Caribbean, discrimination, gender-based violence

\section{Introduction}

$\mathbf{T}$ He Universal Declaration of human rights guarantees every human equal and inalienable rights based on dignity, equality, and mutual respect (UN General Assembly 1948). However, prevalent transphobia and gender-based violence (GBV) deprive transgender (trans) women not only of their fundamental rights but also of their very personhood (United Nations Development Programme et al. 2016). GBV includes physical, sexual, economic, and emotional abuse. GBV also includes discrimination that violates human rights, such as being denied basic necessities; being arbitrarily stopped, detained, or incarcerated; and being refused healthcare and other services (UNFPA et al. 2015). GBV is often directed at trans women because their gender identity* $^{*}$ and gender expression ${ }^{\dagger}$ are perceived as not conforming to social norms and expectations (Inter-American Commission on Human Rights 2015; UN OHCHR 2011a; United Nations Development Programme et al. 2016).

Violence is compounded by transphobia that is institutionalized in many countries in Latin America and the Caribbean (LAC), and globally through legal codes that criminalize trans women's sexual behavior (Beck et al. 2015) and statutes relating to "public decency" and "morality," which "easily lend themselves to arbitrary and discriminatory interpretations" (PAHO et al. 2014) by police and other legal officials (Global Commission on HIV and the Law 2012). Most countries do not have antidiscrimination laws that specifically protect trans people or mechanisms allowing people to legally affirm their gender, for example, by changing their gender marker on official documents (Carroll 2016; Champine et al. 2017). Not having identification documents that correspond to their gender identity limits trans women's access to education, healthcare, and the formal labor market, hindering their social and economic development (Grant et al. 2011; UNDP 2013).

Transphobia and GBV contribute to trans women's vulnerability to mental and physical health issues, including depression, anxiety, suicide (De Santis 2009; Ganju and Saggurti 2017; United Nations Development Programme et al. 2016) human immunodeficiency virus (HIV), sexually transmitted infections (STIs), and STI-related cancers (Baral et al. 2013; Blondeel et al. 2016; De Santis 2009; Ganju and Saggurti 2017; Logie et al. 2017; Wheeler 2014). Trans women have a 49-fold increased odds of HIV infection compared to the general population of reproductive age (Baral et al. 2013).

Internalized transphobia diminishes trans women's agency and social support and increases risky sexual behavior, exacerbating their poor health outcomes (De Santis 2009; Ganju and Saggurti 2017). Moreover, service providers, including

\footnotetext{
*A person's internal, deeply felt sense of being male, female, or some alternative gender, which for transgender women does not correspond to the male sex they were assigned at birth.

${ }^{\dagger}$ A person's ways of communicating their gender externally through physical appearance, behavioral patterns, and so on.
}

healthcare workers and police, refuse to serve trans women or perpetrate violence against them with impunity (Beck et al. 2015; De Santis 2009; Evens et al. 2018; Logie et al. 2017; Poteat et al. 2013; The Caribbean Vulnerable Communities Coalition et al. 2012). This complex web of multiple, cooccurring, and mutually reinforcing health conditions and social inequities increases vulnerability and worsens the health status of trans women, a cycle termed "syndemics", (Brennan et al. 2012; Singer and Clair 2003).

As a result, mortality among trans women is extremely high, especially in LAC, where trans women's estimated life expectancy is 30-35 years (Inter-American Commission on Human Rights 2015). Moreover, 78\% of the 2609 globally reported murders of trans and gender diverse people between 2008 and 2017 were committed in LAC (Trans Respect versus Transphobia Worldwide 2017). While the trans community has been working for decades to gain visibility and access to rights, trans women continue to experience pervasive social marginalization and abuse by family, community members, intimate partners, police, educators, sex work clients, healthcare workers, and other state actors, perpetrated across their lifespan (Beck et al. 2015; Bhattacharjya et al. 2015; Blondeel et al. 2018; De Santis 2009; Divan et al. 2016; Evens et al. 2018; Ganju and Saggurti 2017; Grossman et al. 2005; Logie et al. 2017; Lombardi et al. 2001; Poteat et al. 2013). Trans women are also mistakenly targeted with homophobic violence, as many people continue to remain ignorant of the distinction between gay men and other men who have sex with men, and trans women. The reported prevalence of physical and sexual violence experienced by trans people is markedly higher even than other targeted groups-such as lesbian, gay, bisexual, and intersex people (Blondeel et al. 2018).

The United Nations (UN) system has expressed its concern at the extent and gravity of human rights violations perpetrated against individuals based on their sexual orientation and gender identity (UN OHCHR 2011b). Investigations by the UN High Commissioner for Human Rights found evidence of a pattern of violence and discriminatory laws and practices affecting lesbian, gay, bisexual, trans, and intersex (LGBTI) people in all regions, leading UN entities to issue a joint statement in 2015, calling on states to act urgently to end violence and discrimination against LGBTI adults, adolescents, and children (ILO et al. 2015). As part of this effort, the UN High Commissioner for Human Rights has called for better evidence regarding the prevalence and types of human rights violations against LGBTI people (UN OHCHR 2015).

Moreover, there is a gap in the evidence around the types of abuse trans women experience in LAC and globally (Blondeel et al. 2018; PAHO et al. 2014; Reisner et al. 2016) and the effect of GBV and human rights violations on the health of trans people (Blondeel et al. 2018; Reisner et al. 2016). Trans activists in the region are supportive of research on transgender violence, as their requests for state attention are often met with requests for proof of a problem. Existing documentation on violence against trans women 
often falls under a broader LGBTI umbrella that does not distinguish their unique needs (Divan et al. 2016; United Nations Development Programme et al. 2016). Additional evidence is needed to advocate for adoption and implementation of policies that respect and protect the rights of trans people and inform programs and services that better meet their needs.

This article aims to provide a deeper understanding of the GBV perpetrated against trans women in education, in healthcare, from police, and in other state institutions in select LAC countries and how this GBV prevents trans women from realizing their health and human rights. This analysis was conducted as part of a larger study that also interviewed female sex workers and men who have sex with men regarding their experiences of GBV across their lifespan (Evens et al. 2018). The study was conducted by the United Nations Development Programme (UNDP) LINKAGES, an HIV service delivery project for key populations affected by HIV (led by FHI 360 and supported by United States Agency for International Development [USAID] and President's Emergency Plan for AIDS Relief [PEPFAR]); and The University of the West Indies (UWI).

GBV is a known risk factor for HIV transmission and a barrier to HIV service utilization (Brennan et al. 2012; Decker et al. 2013, 2015; Dunkle and Decker 2013; Logie et al. 2017; Mendoza et al. 2017; Schafer et al. 2012). We sought to better understand key populations' experiences of GBV to (1) more effectively identify and prevent GBV among members of key populations, (2) offer relevant, tailored support for GBV victims within HIV prevention, care, and treatment services, and (3) support the development of laws and policies to prevent and respond to GBV against key populations.

\section{Materials and Methods}

In 2016, LINKAGES, UNDP, and UWI worked with local organizations providing services to trans women in San Salvador, El Salvador; Port of Spain, Trinidad and Tobago; Bridgetown, Barbados; and Ouanaminthe, Jacmel, and Port $\mathrm{Au}$ Prince, Haiti, to conduct structured interviews on their experiences of GBV. The study used a participatory approach, engaging trans women throughout the research process, to ensure that it was responsive to their needs, built their capacity to conduct research, and increased data quality (De Santis 2009; Winter et al. 2016). Regional and national advisory groups were formed-including civil society organizations (CSOs) led by trans women, UN agencies, USAID, and government representatives - to give input on study design, implementation, results, interpretation, and utilization of findings.

\section{Ethics approvals, training, recruitment, and consent}

The study received approval from ethics committees at FHI 360 and in each study country. Twelve trans women were trained in qualitative research, interviewing skills, study procedures, and research ethics, and served as data collectors with support from local researchers. Data collectors recruited study participants for interviews from CSO offices and through outreach activities. All study participants were 18 years of age or older and either self-identified as trans women or, in responding to a two-question participant eligibility questionnaire, noted that they were assigned male at birth and now identified as women (Sausa et al. 2009). All participants provided oral informed consent before participating in the interview.

\section{Data collection}

Interviews were conducted in a private space. Structured interview guides covered experiences of GBV in education, in healthcare, from police, and in other state institutions. For each context, data collectors used open-ended questions to ask participants to share any experiences of GBV and a set of closed-ended questions to ask about specific experiences (e.g., has a healthcare provider ever refused to treat you?). Participants were also asked to share any positive experiences they had to better understand what participants considered to be helpful interactions with service providers. Interview guides were informed by existing GBV research, the study advisory groups, and pilot testing. Interviews were audio-recorded and transcribed verbatim in English, Spanish, or Haitian Creole, and then translated into English.

\section{Data analysis}

Interview data from Barbados, Trinidad and Tobago, and El Salvador were coded in QSR NVivo (QSR Software 2015) by a team of six analysts at FHI 360 using a detailed codebook that included both structural and emergent codes (Guest et al. 2011; Tolley et al. 2016). Analysts independently coded transcripts and compared coding, resolving discrepancies through discussion until intercoder agreement was achieved. After that, intercoder agreement was assessed periodically, with $20 \%$ of transcripts being coded by multiple analysts to assess agreement (Guest et al. 2011; Tolley et al. 2016). Following this analysis, transcripts from Haiti were coded in MS Excel using structural codes, as these interviews were shorter and provided fewer details.

The analysts ran code reports in NVivo for each country and context of GBV (education, healthcare, police, and other state institutions), categorizing experiences of GBV into five types: emotional, physical, sexual, economic, and other human rights violations (UNFPA et al. 2015; WHO et al. 2013), and then further reducing and organizing the data into themes (Guest et al. 2011; Tolley et al. 2016).

A descriptive quantitative analysis was also conducted to identify the proportion of participants who experienced violence in each context. Demographic information and responses to closed-ended questions were entered in EpiData data entry software (EpiData Association 2010) using double data entry to ensure accuracy, exported to STATA 13 (StataCorp LP 2016), and analyzed descriptively by country.

\section{Data interpretation}

An interpretation meeting was held in each country with the data collectors, advisory groups, and study participants to validate and prioritize findings and develop dissemination plans. Following individual country analyses and interpretation meetings, the analysts merged and summarized the data across countries.

\section{Results}

Seventy-four trans women participated in the study across the four countries (Table 1). Participants' average age was 
Table 1. Participant Demographics

\begin{tabular}{|c|c|c|c|c|}
\hline & $\begin{array}{c}\text { Trinidad and } \\
\text { Tobago/ } \\
\text { Barbados }^{\mathrm{a}}\end{array}$ & Haiti $^{\mathrm{b}}$ & $\begin{array}{c}\text { El } \\
\text { Salvador }\end{array}$ & $\begin{array}{c}\text { All } \\
\text { countries }\end{array}$ \\
\hline No. of participants & 15 & 44 & 15 & 74 \\
\hline Mean age (years) & 32.6 & 28.0 & 31.0 & 29.5 \\
\hline \multicolumn{5}{|c|}{ Highest level of education (\%) } \\
\hline None & 0.0 & 2.3 & 0.0 & 1.4 \\
\hline Primary & 0.0 & 13.6 & 40.0 & 16.2 \\
\hline Secondary & 73.3 & 75.0 & 53.3 & 70.3 \\
\hline University/technical & 26.7 & 6.8 & 6.7 & 10.8 \\
\hline No response & 0.0 & 2.3 & 0.0 & 1.4 \\
\hline $\begin{array}{l}\text { Has paid } \\
\quad \text { employment }(\%)\end{array}$ & 80.0 & 39.5 & 33.3 & 46.6 \\
\hline $\begin{array}{l}\text { Ever engaged in } \\
\text { transactional } \\
\text { sex }(\%)\end{array}$ & 33.3 & 51.1 & 80.0 & 53.3 \\
\hline
\end{tabular}

${ }^{a}$ The sample from Trinidad and Tobago and Barbados were combined because the countries are small, and in-country investigators advised combining the countries to recruit enough participants to reach thematic saturation.

bIn Haiti, stakeholders wanted to include three study sites, so the sample size for that country exceeds that of the other countries.

29.5 years. Seventy percent had completed secondary school; the attainment of at least secondary education was lower in El Salvador compared to the other countries. Paid employment was reported by $46.6 \%$ of participants and was highest in Trinidad and Tobago and Barbados (80.0\%) and lowest in El Salvador (33.3\%). Approximately half of participants reported ever engaging in transactional sex, ranging from $33.3 \%$ in Trinidad and Tobago and Barbados to $80.0 \%$ in El Salvador. A high proportion of participants reported experiencing GBV in education $(85.1 \%)$, in healthcare $(82.9 \%)$, from police $(80.0 \%)$, and in other state institutions $(66.1 \%)$ (Table 2). In each context, the highest proportion of participants reporting violence was from El Salvador (100\% for education, healthcare, and police), except for other state institutions, where the highest proportion was from Trinidad and Tobago and Barbados (80.0\%).

The most common form of GBV in all contexts was emotional abuse. Participant's descriptions of emotional abuse were similar across contexts, including derogatory comments ("look, there he goes," "look what we have here,"), name calling ("gay kingpin," "faggot," "clown,"

Table 2. Percentage of Participants Experiencing Gender-Based Violence, by Context

\begin{tabular}{|c|c|c|c|c|}
\hline & $\begin{array}{c}\text { Trinidad/ } \\
\text { Barbados } \\
(\mathrm{n}=15), \\
\%(\mathrm{n})\end{array}$ & $\begin{array}{c}\text { Haiti, } \\
(\mathrm{n}=44), \\
\%(\mathrm{n})\end{array}$ & $\begin{array}{c}\text { El Salvador } \\
(\mathrm{n}=15) \\
\%(\mathrm{n})\end{array}$ & $\begin{array}{c}\text { All } \\
\text { countries } \\
(\mathrm{n}=74), \\
\%(\mathrm{n})\end{array}$ \\
\hline Education & $61.5(13)$ & $87.5(40)$ & 100.0 (14) & $85.1(67)$ \\
\hline Healthcare & 66.7 (15) & $83.3(42)$ & $100.0(13)$ & $82.9(70)$ \\
\hline Police & $73.3(15)$ & $75.0(40)$ & $100.0(15)$ & $80.0(70)$ \\
\hline $\begin{array}{l}\text { Other state } \\
\text { institutions }\end{array}$ & $80.0(10)$ & $62.5(40)$ & $66.7(12)$ & $66.1(62)$ \\
\hline $\begin{array}{l}\text { Any of these } \\
\text { contexts }\end{array}$ & $93.3(15)$ & $97.6(42)$ & $100.0(15)$ & $97.2(72)$ \\
\hline
\end{tabular}

Some participants chose to skip some questions; therefore, not all participants answered questions about all contexts. "ass-licker," “queen," "bullerman"), scolding, ridicule, teasing, and insults ("He is only good for sex work"). Participants were gossiped about, made fun of, laughed at, "singled out," and addressed in a "disrespectful tone." People commented on their physical appearance and behavior that was perceived as feminine and asked inappropriate questions, including questioning their gender. The abuse often occurred in public, causing participants to feel humiliated, ashamed, and less-than. Verbal abuse was often accompanied by disrespectful nonverbal behavior, including staring, pointing, and avoiding eye contact.

The following are summaries of themes specific to each context, including the types of violence experienced, the perpetrators, and the consequences for trans women. Within each section, the themes are ordered from most to least commonly occurring, as determined by frequencies in the open-ended and close-ended portions of the interview. Findings apply to all four countries unless otherwise noted.

\section{Education}

Participants commonly experienced physical violence and threats of physical violence in school, including being pushed, beaten up, and having water thrown on them. In most cases, fellow classmates were the perpetrators, but school administrators also threatened violence. Physical violence was often accompanied by verbal abuse; participants described that they were sometimes teased and insulted with the intention of starting a physical fight. A participant from Trinidad and Tobago described being physically assaulted by a group of boys, while she was waiting at the bus stop:

In secondary school I was actually beaten up by [...] about eight or nine boys [...] for being queer [...] I remember an evening after school me and some friends was waiting for the school bus to come and pick us up, and all these fellas decided to just come charging. [...] When I started to run now and they actually caught up to me, it's only then I had to curl myself in a ball, cover [...] while it was just kicks passing on the floor. And all I could have done at the end of it all is just pick myself up and pretend I wasn't hurt or I wasn't in pain or I wasn't sad [...] to make me look in front of everybody else as strong. (Trinidad and Tobago, age 26)

Some participants were sent home from school, received failing grades, were suspended or expelled, or were threatened with these because of their gender expression, particularly in El Salvador. Experiences ranged from teachers not wanting to touch or grade their assignments to having passing grades retracted by school faculty.

Some participants experienced violence while using the restroom, including being insulted or harassed. Some participants described being extorted or blackmailed at school, while a small number reported sexual harassment.

Participants reported about not feeling accepted, being excluded from group activities, and not feeling at liberty to be themselves at school.

They [other students] would have given me a hard time [...] I have to live like I'm in a straightjacket [...] I can't be myself, I cannot be free [...] I am under rules 
and regulations to be like a normal person. I'll always remember "Ok, I'm in school, I cannot do something this way ... I can't laugh this way." I have to be a certain way to be in a certain group so that they wouldn't talk about me. (Trinidad and Tobago, age 28)

Experiences of GBV in school made participants feel humiliated, embarrassed, and angry about being treated unfairly. A few participants described more severe emotional responses, such as having suicidal thoughts. Some participants did not pass classes or graduate as a result of the discrimination against them. Others switched schools, dropped out, or continued with their schooling from home to avoid further discrimination.

\section{Healthcare}

GBV in healthcare settings was usually perpetrated by healthcare workers and administrative staff, but also by other patients. Many participants said that healthcare staff blamed their health issues on their sexuality, gender identity, or sexual behavior, or assumed that they had HIV because of their gender identity. While this was reported in every country, it was particularly common in Haiti and El Salvador.

I went to hospital when I didn't feel good. When I reached there, I met a nurse. [...] When I explained to her what happened, she answered me that's what happened to me because of the way I am. Without that I wouldn't be in that situation. I felt really mad. (Haiti, age 25)

Participants in every country talked about being made to wait or given lower priority than other patients because of their gender identity or sexual preference.

The nurse in charge of weighing the patients told me,

"look, we're going to leave you for last, because of

how you are." So I felt bad when that happened. (El

Salvador, age 26)

Some trans women were denied health services for themselves or a family member they were accompanying, particularly in El Salvador. Some healthcare staff told them directly they were being denied because they were "different" and they should get health services elsewhere. In other cases, denial of services was more discreet. Staff said they were unable to find their medical records, or switched the patient to a different doctor without explanation. One participant described being denied surgery because nurses were unsure whether she should be treated in the men's or women's health services.

Because of my gender identity, they didn't perform the surgery on me that they were going to perform because they transferred me to the women's surgery room, and they discriminated against me there. They didn't take me in because I showed up with a man's name. [...] I felt like I wasn't really taken into account as a person and they violated my rights. (El Salvador, age 26)

Participants described receiving substandard or neglectful care. They described providers being uncomfortable with trans patients, disdainful of them, or not considering them worthy of high-quality care. Participants felt that healthcare providers "tend to not want to hear what you have to say and what you are experiencing as a trans person" (Trinidad and Tobago, 40). Providers sometimes did procedures quickly; assigned students or less qualified staff to provide care because they did not want to do procedures themselves; and discharged participants quickly without the expected follow-up. It was also common for participants to report that they believed providers had not kept their information confidential.

Several participants in El Salvador said that healthcare providers refused to use their chosen name or to recognize their identity as a woman either because they were dressed like a man or because their identity card had a male name.

In (hospital), they were going to take a blood test. In the form where my name was, they wrote in large letters [FEMALE NAME]. So, in that moment a health worker told me that they had to call me by that name (self-assigned feminine name). So when they called me, they called me out loud with my (legal) male name. Everybody there was looking at me. I went and, very respectfully, approached them and said, "why did you do that?" She said to me, "Ok. I can't do any of that. Show me your DUI Identity Document and that way I'll call you by the name on there. Because, I'm not going to call you a name different to what appears on your DUI." I came out and I felt bad. I felt uncomfortable. There are times when they take away your motivation, even just to visit health centers, because they don't respect you. (El Salvador, age 27)

Only participants in Haiti reported physical abuse, although participants in all countries reported threats of physical abuse in the healthcare setting.

When I got there for a consultation and that lady came to attend me. She undressed me and said "damn it if I knew you were that type of person I'd take a shot and kill you because I don't like people like you.' As she said it, I pretended to be going outside to buy something and left without doing the other things I came to do. (Haiti, age 29)

As a result of the discrimination they experienced, participants described feeling humiliated, uncomfortable, and "less-than." Some left the clinic without being treated, subsequently going to a healthcare center in another town, going to private health services, or getting medications from another source. Some participants avoided healthcare services altogether because of fear of discrimination or general distrust of providers.

When I go to the hospital the doctors always look at me some type of way, because they see someone who was born male and then became female, they always look at you in a bad way. That's why now, even though I am sick I am not going. (Haiti, age 29)

\section{Police}

Participants in all countries reported that police commonly refused to help them or were negligent in their duties when trans women sought assistance. They described being treated rudely when they went to the police station to make 
reports and being blamed for the crimes committed against them. Participants noted that police often took their information, but did not follow up on their cases.

When I was attacked recently, I went to the police station and my face was cut open and I went in there and the police said, "stop bloodying up the place, don't let your blood get on the desk, don't touch the desk," and he signed the report form, chuck it at me, and then continue to do what he was doing. He didn't attend to me any other way. Because normally they are supposed to take you to the hospital when you come in there bloody or injured, and they did not. (Barbados, age 25)

They should treat us the same way like a woman. [When] they see we are a transvestite, like they don't care about what happen, they don't care about the violence. They are trying to tell us that we cause it on our own self. (Trinidad and Tobago, age 33)

Participants experienced physical violence and threats of violence from the police. This form of GBV was also perpetrated by soldiers in El Salvador. Punches and slaps were most commonly reported, but a few participants were assaulted with police batons, and in one case, thin metal rods. Some threats of physical violence were related to wanting to change participants' gender identity ("We're going to make you into a man by hitting you with our dicks," with "dicks", meaning fists or police batons). Participants were also threatened with guns and tasers.

They treated us like they were going to kidnap us, like criminals. They would completely surround us on all sides, and one day they took me and beat me up, like really beat me up with their batons and everything, and they slapped me, punched my neck so that I would fall over, can you imagine that? They hit me with this baton that I didn't see at that time, and then they took me to the station. (El Salvador, age 44)

Police and soldiers commonly robbed trans women or demanded payment in the form of money or sex, particularly in El Salvador. Participants who engaged in sex work reported that police demanded sex in exchange for allowing them to continue working or not arresting them. Trans women also reported other forms of sexual assault and harassment from police, ranging from sexual comments such as being called "my love" to being groped or raped.

They just told me that if I wanted for them to leave, that I should have sex with them. With all of them. With like five police [...] I did, just so that I could keep working. (El Salvador, age 21)

Some participants in El Salvador and Trinidad reported intimidation from police in the form of stop-and-searches. Police searched participants' bags or pulled them over while driving for no apparent reason. In some cases, body searches were conducted by male officers.

Some were threatened with arrest for minor or unspecified offenses, such as wearing women's clothing, "behaving arrogantly," or being "a crazy," and a few participants in El Salvador and Haiti were arrested or detained because of their gender identity.
While I was standing somewhere talking to a friend, a boy, I was negotiating something with him and the police showed up asking what we were doing, we said we were just talking, but they said "no" because I am looking like a girl. We spent two days in custody. That should not happen because I have the right to stand where I want, [...] but because I have the style of a woman it happened. If there was a justice in Haiti, it should not have happened. (Haiti, age 30)

GBV from police was most commonly perpetrated on the street, but was also perpetrated in sex work establishments like bars and at police stations when trans women sought assistance or were detained. Like other contexts of GBV, participants said that they felt ashamed after experiencing GBV from the police, but the most common consequence was that they did not trust the police and did not seek help from them.

I would like it to be taught at the police academy that they should respect people's rights, that they should know everyone is a person and everyone is free; they have their own choices. (Haiti, age 29)

I would like for the police to pay more attention to you and to help you the way they should, just like with any other person, treat you the same. [...] Same goes for health, that they should help you, not discriminate against you, not single you out for who you are. They should treat you like a regular person, normal, just like everyone else who is waiting there at the clinic. (El Salvador, age 26)

\section{Other state institutions}

Participants reported experiencing GBV when they went to get their government-issued identity cards, passports, and in Haiti, electoral cards because their sex assigned at birth was male, but they had a feminine gender expression or were perceived to be homosexual. In addition to experiencing verbal abuse, they were made to wait longer than other clients. In El Salvador and Haiti, several participants were forced to alter their physical appearance to get their identity card. Some participants in Haiti said they were outright refused an identity card. Participants described these experiences as humiliating, in part, because discrimination occurred in front of other people.

I was about to do my electoral card, but I had woman dress and hair they told me they won't do it for me, I have to go to my house cut my hair and take the woman clothes off to do the card [...] I felt very humiliated because they had lot of people there too, it was only for me they didn't do the card because I am a homosexual, I have long hair. Everybody was laughing at me. (Haiti, age 26)

Participants also experienced discrimination while using their ID card or passport because the sex listed on the card did not match their gender expression. One participant in Barbados said she has been called "sir" or "mister" because she is listed as male on her identity card: "In Barbados you have male/female [on the passport], there's no trans [...] that's an issue that needs to be dealt with." Participants from Trinidad and Tobago talked about having to undergo additional 
security screening at the airport, where security lines are divided by sex, and having difficulty cashing checks at the bank because the checks were made out to a different name than what appeared on their identity card.

\section{Positive experiences}

Some participants talked about having positive experiences with healthcare providers, police, educators, and employees in identification document centers. They described service providers who were respectful and supportive, and made the effort to meet their specific needs as trans women. Participants appreciated having their gender identity affirmed by being called by their chosen name and pronoun. Participants noted that when they were treated well by healthcare providers, they returned to that provider or clinic for care. Some participants said that the emotional support and encouragement from teachers helped them persevere through the discrimination they faced and to pursue higher education. Some participants said that it was positive when service providers treated them like any other citizen and did their job without discriminating against them for being trans.

There was a time when my apartment was broken into. I called the police. They came. It was refreshing to see them do their job. Cause of course in the back of your head, you're thinking “oh, Lord. They're gonna come here, [...] they're gonna see who you are, and it's gonna be very negative." [...] It was different, and I was like, "What? Wow!" And I complimented them. I said, "I'm so glad you all did your job." They came, they asked questions, they got my sex right. They were professional. [...] It was so refreshing. (Barbados, age 37)

\section{Discussion}

Trans women in this study experienced pervasive GBV in healthcare, in education, from police, and in other state institutions. Perpetrators in these contexts were usually service providers, although community members were also responsible for perpetrating GBV. Participants believed the violence they experienced was motivated by others' perceptions of their gender identity or sexual orientation. Participants said that perpetrators perceived them to be "homosexual," "queer," "transvestite," "someone who was born male and then became female," and "looking like a girl." Notably, emotional abuse was the most common form of GBV in all contexts. Physical and sexual violence are commonly recognized as forms of GBV; however, emotional violence can be more insidious and socially acceptable, making it more difficult to combat.

As a result of the GBV they experienced, participants were unable to access the services they needed. They left health clinics, police stations, school, and identification document centers after being discriminated against. Some avoided these services altogether because they feared discrimination or distrusted providers. Participants also noted that their needs as trans women usually went unmet. Finding providers who were aware of their needs and made the effort to meet them was the exception.

The study results suggest that additional work is needed to promote the rights of trans women in LAC and reduce and respond to GBV against them. The broad challenge is to shift the social norms that promote male privilege and the idea that sex assigned at birth dictates gender identity. As this shift occurs over time, we recommend the following immediate actions, based on the study findings, to mitigate GBV against trans women. Our recommendations are consistent with recommendations from other literature on violence against trans individuals (Cobos and Jones 2009; De Santis 2009; Divan et al. 2016; Ganju and Saggurti 2017; Logie et al. 2017; Reisner et al. 2016) and policy guidance from UN agencies, the Pan American Health Organization, and the World Health Organization (add Blueprint; transgender people and HIV; Legal Gender Recognition).

\section{Gender-affirming laws and policies}

Participants experienced GBV when obtaining stateissued identity documents or when using identity documents that conflicted with their gender identity. These experiences underscore the urgent need for gender identity laws in these countries that guarantee trans women's sociocultural and political rights. In addition, trans women should be able to self-determine the name and gender that appears on other official documents, including school and medical records (Winter et al. 2016), without having to meet any preconditions such as sex reassignment surgery, hormone therapy, or any form of diagnosis (Reisner et al. 2016). UNDP calls gender recognition "an essential requirement for trans people to attain full personhood and citizenship" that "can immeasurably support their empowerment and act as an acknowledgment of their dignity and human worth, changing the way they are perceived by their families, by society in general, and by police, government actors, and healthcare personnel" (Divan et al. 2016).

In addition to gender identity laws, antidiscrimination laws that specifically prohibit discrimination based on sexual orientation and gender identity are needed, as well as legal remedies for trans women who have been subjected to GBV. While the development of legal frameworks in line with international human rights declarations is an important step, equality for trans people requires the design and implementation of public policies that go beyond eliminating discrimination and violence, toward enabling conditions for all trans women to live lives to their full potential (UN OHCHR 2008).

For example, in Argentina, UNDP supported the Gender and Sexual Diversity unit of the Ministry of Labor to facilitate the inclusion of trans people in the National Youth Programme and the Training and Employment Insurance Programme, helping ensure that trans people could complete primary and secondary education, access job training, participate in employment support workshops, and receive financial support to start business ventures. Also in Argentina, the National Program for Sexual Health \& Responsible Parenthood published comprehensive guidance on healthcare for trans people in the context of the Gender Identity Law. In addition to initiatives such as these, we recommend that national police services and security apparatus implement antiprofiling and antibias policies that include transgender people (National Center for Transgender Equality 2015). Finally, ministries of education should adopt antidiscrimination and antibullying policies that include students of all 
sexual and gender identities to make schools safer for transgender students (Kull et al. 2015; U.S. Department of Health and Human Services 2017).

\section{Sensitizing service providers}

When participants sought services-either to address GBV they had experienced or to meet other needs-they were often faced with further discrimination from service providers, including healthcare workers and administrators, police, soldiers, educators, and employees in identification document centers. Trans women were unable to get the services they needed and were often hesitant to return, contributing to a cycle of vulnerability and unmet need. Poteat and colleagues observed similar discrimination in their study of transgender healthcare in the United States. They suggested that "negative attitudes [from healthcare providers] toward [trans individuals] can serve as a psychological defense against discomfort with gender nonconformity."

Training service providers to offer trans-competent and gender-affirming services can help them be more accepting of trans women and better able to meet their needs (Poteat et al. 2017; Programa Nacional de Salud Sexual y Procreacion Responsable et al. 2015; Reisner et al. 2016). Trainings also provide opportunities for trans women to share their needs and experiences directly with providers and to interact in a positive way that can minimize stigma and improve provider attitudes (Logie et al. 2017; Poteat et al. 2017).

In addition to training on sexual and gender diversity and human rights, providers should be sensitized to the various forms of GBV, namely that GBV extends beyond physical and sexual violence, and that emotional and economic violence and refusing services violate trans women's human rights. Providers also need to know how to provide services to victims of GBV and where to refer them for additional services. Collectively, these efforts can create an enabling environment for trans women to finish their education, receive quality health services, and access justice. Efforts to change norms and behaviors among these actors should be evaluated so that effective interventions can be scaled up as part of preservice training.

In response to these study findings, LINKAGES is training healthcare workers in several LAC countries to provide genderaffirming care, including using correct names and pronouns; recording sex assigned at birth separately from gender identity; detecting cases of violence; and appropriately responding to and referring victims. LINKAGES is also training police to understand who transgender people are, their human rights, and the need for stigma-free police services.

\section{Limitations}

Some limitations of the study methodology are worth noting. Study participants were purposively selected by organizations and peers providing services to trans women. As such, the participants in this study may be more connected to trans-specific social services and peer networks than other trans women, and as a result of these connections, may be more empowered or have more support than those not connected with a trans community. The findings are not necessarily representative of all trans women's experiences in these countries and may not be generalizable to other countries. GBV is a sensitive topic that some participants may not have discussed in-depth previously. As such, they may not have felt comfortable sharing all their experiences, or may not have recognized their experiences as GBV. Having peer data collectors helped address these limitations by making participants feel more at ease and free to share.

The interview guides covered 13 different contexts. Participants could skip contexts they did not want to talk about or where they did not think they had experienced GBV; nonetheless, interviews were long and of varying quality and depth. Interviews conducted in El Salvador were extremely rich and detailed, while interviews in Haiti were much shorter. Nonetheless, results were more similar across countries than they were different, and interviews in all four countries helped gain important insights into trans women's experiences and potential places to intervene to improve their health and well-being.

\section{Conclusions}

The trans women in this study experienced pervasive GBV in healthcare, in education, from police, and in other state institutions in Barbados, El Salvador, Haiti, and Trinidad and Tobago. Service providers in these contexts not only failed to meet the specific needs of this population but also discriminated against them, exacerbating their economic, health, and social vulnerability. Although international and regional resolutions call for the legal protection of transgender people, states do not meet these obligations. To respect, promote, and fulfill trans women's human rights, governments should enact and enforce antidiscrimination and gender-affirming laws and policies. Governments should also sensitize providers to deliver gender-affirming services.

\section{Acknowledgments}

First and foremost, we would like to thank the study participants. During the course of the study, several trans women in participating countries were murdered. We mourn their loss and appreciate the bravery of all those willing to come forward to share their stories, even as they grieved for members of their community. We would like to thank the peer data collectors: Camila Vargas, Nissa Kahory Sánchez, and B.M.C. (El Salvador); B.R. (Trinidad and Tobago); D.E. (Barbados); and Wilfrid Junior Moril, Palemon Wikenson, Veillard Reginald, Caimitte Jn Elie, and Clifford Cherisier (Haiti).

We would like to acknowledge the CSOs that supported the study and assisted with recruitment: Friends for Life, CARe, and the Family Planning Association of Trinidad and Tobago (Trinidad and Tobago); Community Education Empowerment \& Development, EQUALS, Jabez House, and B-Glad (Barbados); Asociación Diké de Personas Transgénero y LGBTI+, ASPIDH Arcoíris, and COMCAVIS-TRANS (El Salvador); and Arc en Ciel, ANAPFEH, Facdis, FEBS, FOSREF, GHESKIO, Gran Lakou, Kouraj, ORAH, and Serovie (Haiti). We would like to thank the Innovative Response Globally for Trans Women and HIV for their help developing and piloting the interview guide. These and other organizations and individuals are advocating for the visibility and equality of trans women, and often face violence as they serve the trans community. We would also like to thank The UWI HIV \& AIDS Response Programme, our local implementing partner in Trinidad and Tobago and Barbados, and the LINKAGES team in Haiti. 
This document was made possible by the generous support of the American people through the USAID and the U.S. PEPFAR, as well as by the UNDP. The contents are the responsibility of the LINKAGES project and do not necessarily reflect the views of USAID, PEPFAR, the United States Government, or UNDP. LINKAGES, a 5-year cooperative agreement (AID-OAA-A-14-00045), is the largest global project dedicated to key populations. LINKAGES is led by FHI 360 in partnership with IntraHealth International, Pact, and the University of North Carolina at Chapel Hill.

\section{Author Disclosure Statement}

No competing financial interests exist.

\section{References}

Baral SD, Poteat T, Strömdahl S, et al. (2013). Worldwide burden of HIV in transgender women: A systematic review and meta-analysis. Lancet Infect Dis. 13, 214-222.

Beck J, Peretz JJ, Ayala G. (2015). Services Under Siege: The Impact of Anti-LGBT Violence on HIV Programs. (Global Forum on MSM \& HIV, Oakland, CA.)

Bhattacharjya M, Fulu E, Murthy L, et al. (2015). The Right(s) Evidence-Sex Work, Violence and HIV in Asia: A Multi-Country Qualitative Study. (United Nations Population Fund, United Nations Development Fund, Asia Pacific Network of Sex Workers, and Centre for Advocacy on Stigma and Marginalization, Bangkok.)

Blondeel K, de Vasconcelos S, García-Moreno C, et al. (2018). Violence motivated by perception of sexual orientation and gender identity: A systematic review. Bull World Health Organ. 96, 29L-41L.

Blondeel K, Say L, Chou D, et al. (2016). Evidence and knowledge gaps on the disease burden in sexual and gender minorities: A review of systematic reviews. Int J Equity Health. 15, 16.

Brennan J, Kuhns LM, Johnson AK, et al. (2012). Syndemic theory and HIV-related risk among young transgender women: The role of multiple, co-occurring health problems and social marginalization. Am J Public Health. 102, 1751-1757.

Carroll A. (2016). State-Sponsored Homophobia: A World Survey of Sexual Orientation Laws, Criminalisation, Protection and Recognition. (International Lesbian, Gay, Bisexual, Trans, and Intersex Association, Geneva.)

Champine RD, Williams R, Berman-Vaporis I, et al. (2017). The legality of gender change. 2018. Retrieved from www.nationalgeographic .com/magazine/2017/01/gender-identity-map-where-you-can-changeyour-gender-on-legal-documents (accessed July 5, 2018).

Cobos DG, Jones J. (2009). Moving forward: Transgender persons as change agents in health care access and human rights. J Assoc Nurses AIDS Care. 20, 341-347.

De Santis JP. (2009). HIV infection risk factors among male-to-female transgender persons: A review of the literature. J Assoc Nurses AIDS Care. 20, 362-372.

Decker MR, Crago A-L, Chu SK, et al. (2015). Human rights violations against sex workers: Burden and effect on HIV. Lancet. 385, 186-199.

Decker MR., Wirtz AL, Pretorius C, et al. (2013). Estimating the impact of reducing violence against female sex workers on HIV epidemics in Kenya and Ukraine: A policy modeling exercise. Am J Reprod Immunol. 69(Suppl 1), 122-132.

Divan V, Cortez C, Smelyanskaya M, et al. (2016). Transgender social inclusion and equality: A pivotal path to development. J Int AIDS Soc. 19(Suppl 2), 20803.

Dunkle KL, Decker MR. (2013). Gender-based violence and HIV: Reviewing the evidence for links and causal pathways in the general population and high-risk groups. Am J Reprod Immunol. 69(Suppl 1), 20-26.
EpiData Association. (2010). EpiData-Comprehensive Data Management and Basic Statistical Analysis System. (EpiData Association, Odense.)

Evens E, Lanham M, Santi K, et al. (2018). Experiences of genderbased violence among FSWs, MSM, and transgender women in Latin America and the Caribbean: A mixed methods analysis to inform HIV programming. BMC International Health and Human Rights. Under review.

Ganju D, Saggurti N. (2017). Stigma, violence and HIV vulnerability among transgender persons in sex work in Maharashtra, India. Cult Health Sex. 19, 903-917.

Global Commission on HIV and the Law. (2012). HIV and the Law: Risks, Rights and Health. (United Nations Development Programme, New York, NY.)

Grant JM, Mottet LA, Tanis J, et al. (2011). Injustice at Every Turn: A Report of the National Transgender Discrimination Survey. (National Center for Transgender Equality and National Gay and Lesbian Task Force, Washington, DC.)

Grossman AH, D'Augelli AR, Howell TJ, et al. (2005). Parents' reactions to transgender youths' gender nonconforming expression and identity. J Gay Lesbian Soc Serv. 18, 3-16.

Guest G, MacQueen KM, Namey EE. (2011). Applied Thematic Analysis. (Sage, Thousand Oaks, CA.)

ILO, OHCHR, UNAIDS, et al. (2015). Ending Violence and Discrimination Against Lesbian, Gay, Bisexual, Transgender and Intersex People. (Geneva.) Retrived from http://www.unaids.org/ sites/default/files/2015029_Joint_LGBTI_Statement_en.pdf (accessed August 17, 2018).

Inter-American Commission on Human Rights. (2015). Violence Against Lesbian, Gay, Bisexual, Trans and Intersex Persons in the Americas. (The Organization of American States, Washington, DC.)

Kull RM, Kosciw JG, Greytak EA. (2015). From Statehouse to Schoolhouse: Anti-Bullying Policy Efforts in U.S. States and School Districts. (GLSEN, New York, NY.)

Logie CH, Lacombe-Duncan A, Kenny KS, et al. (2017). Associations between police harassment and HIV vulnerabilities among men who have sex with men and transgender women in Jamaica. Health Hum Rights. 19, 147.

Lombardi EL, Wilchins RA, Priesing D, et al. (2001). Gender violence: Transgender experiences with violence and discrimination. J Homosex. 42, 89-101.

Mendoza C, Barrington C, Donastorg Y, et al. (2017). Violence from a sexual partner is significantly associated with poor HIV care and treatment outcomes among female sex workers in the Dominican Republic. J Acquir Immune Defic Syndr. 74, 273-278.

National Center for Transgender Equality. (2015). Reforming police and ending anti-transgender violence. In A Blueprint for Equality: A Federal Agenda for Transgender People. HJ Tobin, R FreedmanGurspan, L Mottet, eds. (National Center for Transgender Equality, Washington, DC) pp. 27-30.

PAHO, John Snow, Inc., World Professional Association for Transgender Health. (2014). Blueprint for the Provision of Comprehensive Care for Trans Persons and Their Communities in the Caribbean and Other Anglophone Countries. (John Snow, Inc., Arlington, VA.)

Poteat T, German D, Kerrigan D. (2013). Managing uncertainty: A grounded theory of stigma in transgender health care encounters. Soc Sci Med. 84, 22-29.

Poteat T, Park C, Solares D, et al. (2017). Changing hearts and minds: Results from a multi-country gender and sexual diversity training. PloS One. 12, e0184484.

Programa Nacional de Salud Sexual y Procreacion Responsable, Tenemos Patria, Ministerio de Salud de Argentina. (2015). Comprehensive Health Care for Trans People: Guide for Health Teams [in Spanish]. Buenos Aires. (Programa Nacional de Salud Sexual y Procreacion Responsable.) 
QSR Software. (2015). NVivo Qualitative Data Analysis Software Doncaster. (QSR International Pty Ltd.)

Reisner SL, Poteat T, Keatley J, et al. (2016). Global health burden and needs of transgender populations: A review. Lancet. 388, 412-436.

Sausa L, Sevelius J, Keatley J, et al. (2009). Policy Recommendations for Inclusive Data Collection of Trans People in HIV Prevention, Care \& Services. (Center of Excellence for Transgender HIV Prevention, University of California, San Francisco, San Francisco, CA.)

Schafer KR, Brant J, Gupta S, et al. (2012). Intimate partner violence: A predictor of worse HIV outcomes and engagement in care. AIDS Patient Care STDS. 26, 356-365.

Singer M, Clair S. (2003). Syndemics and public health: Reconceptualizing disease in bio-social context. Med Anthropol Q. 17, 423-441.

StataCorp LP. (2016). Stata/SE 13.1 for Windows. (StataCorp LP, College Station, TX.)

The Caribbean Vulnerable Communities Coalition, El Centro de Orientación e Investigación Integral, Pan Caribbean Partnership Against HIV and AIDS, et al. (2012). Focus Right: Diversity and Commonality-A Look at Female and Transgender Sex Workers in Three Caribbean Countries. (Dominican Republic, Santo Domingo.)

Tolley EE, Ulin PR, Mack N, et al. (2016). Qualitative Methods in Public Health: A Field Guide for Applied Research. (John Wiley \& Sons, San Francisco, CA.)

Trans Respect Versus Transphobia Worldwide. (2017). TMM UpdateTrans Day of Remembrance 2017. Transgender Europe's Trans Murder Monitoring Project. Retrieved from https://transrespect.org/ en/tmm-update-trans-day-remembrance-2017/ (accessed November 6, 2017).

UN General Assembly. (1948). Universal Declaration of Human Rights. (UN General Assembly, Paris.)

UN OHCHR. (2008). The Right to Health: Fact Sheet 31. (Office of the United Nations High Commissioner for Human Rights, Geneva.)

UN OHCHR. (2011a). Discriminatory Laws and Practices and Acts of Violence Against Individuals Based on Their Sexual Orientation and Gender Identity. Report of the United Nations High Commissioner for Human Rights. (Geneva.)

UN OHCHR. (2011b). Resolution on Human Rights, Sexual Orientation and Gender Identity. Office of the United Nations High Commissioner for Human Rights. (Geneva.)
UN OHCHR. (2015). Discrimination and Violence Against Individuals Based on Their Sexual Orientation and Gender Identity. Report of the United Nations High Commissioner for Human Rights. (Geneva.)

UNDP. (2013). Transgender Health and Human Rights: Discussion Paper. (United Nations Development Programme, New York, NY.)

UNFPA, Global Forum on MSM \& HIV, UNDP, et al. (2015). Implementing Comprehensive HIV and STI Programmes with Men Who Have Sex with Men: Practical Guidance for Collaborative Interventions. (United Nations Population Fund, New York, NY.)

United Nations Development Programme, IRGT: A Global Network of Transgender Women and HIV, United Nations Population Fund, et al. (2016). Implementing Comprehensive HIV and STI Programmes with Transgender People: Practical Guidance for Collaborative Interventions (the "TRANSIT"). (United Nations Development Programme, New York, NY.)

U.S. Department of Health and Human Services. (2017). Bullying of LGBT Youth and Those Perceived to Have Different Sexual Orientations. (Washington, DC.) Retrieved from https://www.stop bullying.gov/sites/default/files/2017-09/lgbtyouthtipsheet.pdf (accessed August 17, 2018).

Wheeler J, Anfinson K, Valvert D, et al. (2014). Is violence associated with increased risk behavior among MSM? Evidence from a population-based survey conducted across nine cities in Central America. Glob Health Action. 7, 24814.

WHO, UNFPA, UNAIDS, et al. (2013). Implementing Comprehensive HIV/STI Programmes with Sex Workers. Practical Approaches from Collaborative Interventions. (World Health Organization, Geneva.)

Winter S, Settle E, Wylie K, et al. (2016). Synergies in health and human rights: A call to action to improve transgender health. Lancet. 388, 318.
Address correspondence to: Michele Lanham, $M P H$ FHI 360 359 Blackwell Street, No. 200 Durham, NC 27701

E-mail: mlanham@fhi360.org 